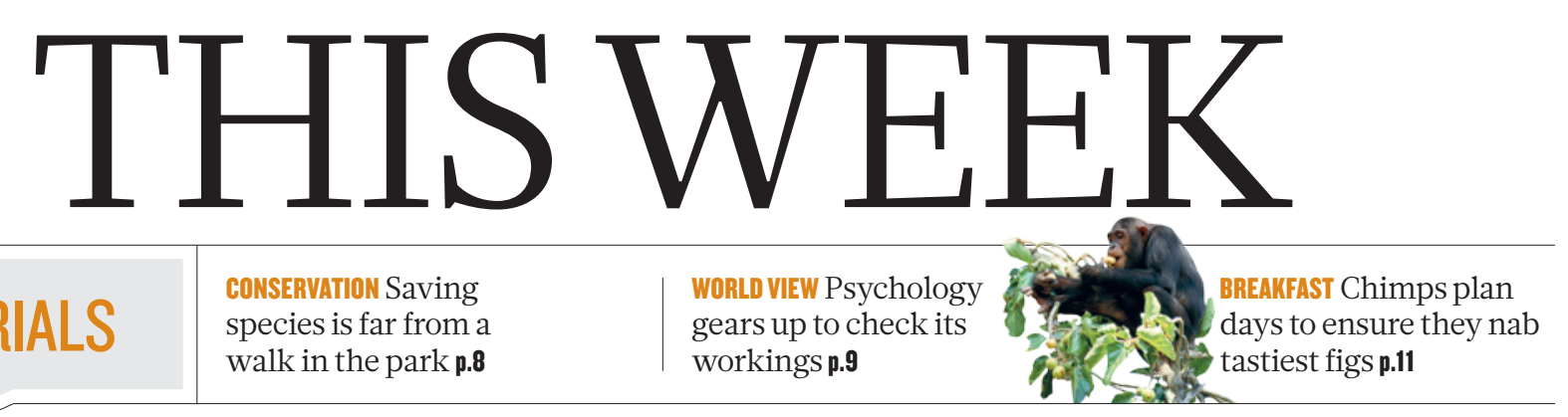

Journals unite for reproducibility

Consensus on reporting principles aims to improve quality control in biomedical research and

encourage public trust in science.

$\mathrm{R}$ eproducibility, rigour, transparency and independent verification are cornerstones of the scientific method. Of course, just because a result is reproducible does not make it right, and just because it is not reproducible does not make it wrong. A transparent and rigorous approach, however, will almost always shine a light on issues of reproducibility. This light ensures that science moves forward, through independent verifications as well as the course corrections that come from refutations and the objective examination of the resulting data.

It was with the goal of strengthening such approaches in the biomedical sciences that a group of editors representing more than 30 major journals; representatives from funding agencies; and scientific leaders assembled at the American Association for the Advancement of Science's headquarters in June 2014 to discuss principles and guidelines for preclinical biomedical research. The gathering was convened by the US National Institutes of Health, Nature and Science (see Science 346, 679; 2014).

The discussion ranged from what journals were already doing to address reproducibility - and the effectiveness of those measures - to the magnitude of the problem and the cost of solutions. The attendees agreed on a common set of Principles and Guidelines in Reporting Preclinical Research (see go.nature.com/ezjl1p) that list proposed journal policies and author reporting requirements in order to promote transparency and reproducibility.

The guidelines recommend that journals include in their information for authors their policies for statistical analysis and how they review the statistical accuracy of work under consideration. Any imposed page limits should not discourage reproducibility. The guidelines encourage using a checklist to ensure reporting of important experimental parameters, such as standards used, number and type of replicates, statistics, method of randomization, whether experiments were blinded, how

the sample size was determined and what criteria were used to include or exclude any data. Journals should recommend deposition of data in public repositories, where available, and link data bidirectionally when the paper is published. Journals should strongly encourage, as appropriate, that all materials used in the experiment be shared with those who wish to replicate the experiment. Once a journal publishes a paper, it assumes the obligation to consider publication of a refutation of that

"The guidelines encourage using a checklist to ensure reporting of important experimental parameters."

source, species, strain, sex, age, husbandry and strain characteristics for transgenic animals. For cell lines, one might report the source, authentication and mycoplasma contamination status. The existence of these guidelines does not obviate the need for replication or independent verification of research results, but should make it easier to perform such replication.

Some of the journals at the meeting had already had all or most of these principles and guidelines in place. But the point is that a large number of scientific journals are standing together in their conviction that reproducibility and transparency are important issues. As partners to the research enterprise in the communication and dissemination of research results, we want to do our part to raise the standards for the benefit of scientists and of society. The hope is that these guidelines will be viewed not as onerous, but as part of the quality control that justifies the public trust in science.

\section{On the mend}

\section{The scientific regeneration of central Europe is gathering pace, but needs further help to thrive.}

\section{$\mathrm{T}$} he peaceful implosion of communism in the autumn of 1989 , almost exactly 50 years after Nazi Germany's assault on Poland triggered the Second World War, was perhaps the brightest moment in Europe's twentieth-century history. The fall of the Berlin Wall restored political and personal freedom to central Europe, where people had endured Hitler's atrocities only to find themselves ruled by Soviet despots. It is a small miracle that the rich learned tradition of the region survived two consecutive tyrannies.
Science in liberated central Europe had to adapt quickly to survive in the free world. Governments, intellectual elites and academic institutions in the region were all equally unprepared for the political sea change that occurred after 1989. A quarter of a century on, the transformation to parliamentarian democracy and a market economy has been achieved. Science was generally not a priority in the early years of the transition. But from 2004 onwards, membership of the European Union (EU) provided a boon that some countries are prudently using to rebuild their research capacities (see page 22). However, despite generous subsidies from Brussels, other countries have a long way to go.

The region's main asset is a growing pool of young talent that is rediscovering science as a worthwhile profession. This generation rightly demands more support and more constructive political vision than some of the region's current governments have to offer. In Romania and Bulgaria, where those in power are stubbornly obstructing reform, science is losing out. And in Hungary, 